\title{
A Critique Of Stephen Downes' Article, "Learning Objects": A Middle Eastern Perspective
}

Osama Shata

Athabasca University

\section{Introduction}

The discipline of computing is definitely influencing and shaping almost every aspect of our life, including education. One decade ago, the WWW was not critical to education. However, nowadays, it has become an integral part of the learning process. A huge number of educational institutes have some form of online courses. This number is increasing tremendously. The quality of an online course depends heavily on the learning material's content and the tools (including images, sound, video, animation) used to accompany the explanation of that learning material. Also, to cope with the rapid advances in the field, the contents of each course must be reviewed within short revision cycles. In addition, the continuous change in many disciplines has broadened the synergy and the overlapping between courses. Moreover, courses must be stored efficiently using computer software that facilitates fast retrieval of their contents. All of the above has made it necessary to seek greater efficiency via: (a) approaches that hasten course design and development, (b) techniques that facilitate sharability between courses, and (c) tools that support reusability of course's components and templates for publishing on the WWW.

These requirements (templates, sharability, reusability, learning objects, computer software, the WWW, and efficient storage) suggest that a promising solution would be to migrate to a database platform that facilitates short cycle development, sharing and reusing of learning material, and publishing to multiple formats. In his article on learning objects in this issue of IRRODL, Downes quotes Wieseler (1999): "Reusable content in the form of objects stored in a database has become the Holy Grail in the e-learning and knowledge management communities."

Use of learning objects is a relatively new technique for designing and implementing learning materials, which enables reusability and sharability between several institutions around the world that offer courses on the WWW. It is relevant to e-learning offered through traditional or distance education institutions. For example, researchers at Athabasca University, a world leader in offering courses at distance, are working on a project that is related to learning objects named SCARO (Sharable Curriculum And Reusable Objects system). 
Researchers from the University of Alberta (a reputable traditional university) are collaborating with national and international researchers on another project that also addresses learning objects: Campus Alberta Repository of Educational Objects (CAREO) [http://www. careo.org/].

In his article, Downes first describes this need for learning objects and identifies their essential components based on this need. He then draws on concepts from recent developments in computer science, describing learning objects from a theoretical perspective. Finally, he describes learning objects in practice, including creation or generation by content authors, and discusses how they are displayed or used by students and other client groups.

In the first part of his article, Downes deals with "the need for and nature of learning objects" (Downes, 2001). He also explains and clarifies the advantages of creating and using learning objects, as well as discussing the nature of learning objects. He provides some examples and emphasizes that learning objects are not at the level of courses but rather at lower levels such as units or more primitive components such as video clips/images. (A unit is part of a course that may be completed by the learner in one session). I believe that the author could have used more detailed examples to clarify the differences between the various levels of learning objects, as well as at which level it is more desirable to make use of learning objects (this could depend on the application). However, Downes does address this point in his references.

When dealing with learning objects from a theoretical perspective, Downes introduces concepts such as object-oriented design. However, he has not clearly explained whether the use of this concept would mean that using an objectoriented database is essential, or if the concept was mentioned only because reusability, one of the main goals of creating learning objects, is enabled through object-oriented design. Would relational, or object-relational databases be used for the purpose of creating objects repositories? Finally, Downes provides useful information about open standards and XML in the context of the article.

In the third part of this article, Downes deals with creating/developing and displaying learning objects in practice. Although the author has made some effort to draw a complete scenario for developing and displaying learning objects, I find this scenario to be incomplete, particularly when it comes to using open source products (other than XML, HTML, etc.). In addition, I believe that this article would benefit from more detailed discussion of the creation of objects repositories and how untraditional learning objects (such as video clips, audio, etc.) may be represented in those repositories. (I understand that the technology needed for creating and using learning objects efficiently is still evolving, especially when it comes to using open source media).

I find that the author has surveyed the topic of learning objects in a comprehensive manner. The article does not introduce new or revolutionary ideas. In addition, the author has referenced a comprehensive, suitable, related, and rep-

International Review of Research in Open and Distance Learning 
A Critique Of Stephen Downes' Article, "Learning Objects": A Middle

Eastern Perspective

utable list of resources. Learning objects, if adopted on a large scale worldwide, can have their positive impacts on e-learning.

\section{Learning Objects: Creation, Development, and Usage in the Middle East}

I will now comment on the feasibility and practicality of developing and using learning objects in the Middle East (ME). I will conclude my review with a discussion of some of the weaknesses of learning objects.

\section{Feasibility and Practicality}

The use of learning objects is focused on sharing and reusing learning materials via the Internet. In his article, Downes assumes that learning objects will be stored in central repositories and copies of the metadata will be available on other distributed computers close to users. Learning objects are to be developed using open source products. The infrastructure for using learning objects would require:

- Computers connected to the Internet. These are already available in all countries in the Middle East, especially in scientific and research institutions. High-speed connections are also available.

- E-mail. This is necessary in order for researchers to share information and to facilitate collaboration on shared work at distance. This is available on a wide scale in the Middle East.

- Web Sites. Having Web sites contributes positively to the development and usage of learning objects. However, many institutions in the Middle East have their web sites and the number is increasing tremendously. Accessing an Intranet is needed; this is available to collaborated institutions as long as they have access to the Internet.

- Learning objects repositories. These may be implemented using the same database products that are already available in other parts in the world.

In addition, many of the institutions in the Middle East use courses and curricula that have many aspects in common to those used in North America and Europe (e.g., in mathematics, computing, arts, etc.). For example, the Centre for Middle Eastern Studies of the University of Texas at Austin [http://menic.utexas. edu/menic/] lists a comprehensive set of links to related sites in the Middle East. Many Middle Eastern countries have information technology (IT) colleges and 
faculties that deliver computer science and IT courses and curricula. Their graduates are well capable of using the products and the technology needed for developing learning objects (see [http://www.uaeu.ac.ae/outreach/mesite/ education.html] and [http://www.cisco.com/warp/public/3/middle_east/ education_UAEUniversity.html] for examples).

The Middle East has the necessary expertise to contribute to developing learning objects. One of the reputable companies in the domain of providing Internet and business class services internationally, CISCO [http://www.cisco.com/warp/ public/3/middle_east/education.html], has devoted part of its web site to the Middle East region. CISCO also has a monthly "Cisco Middle East News" newsletter that shows that many of the products and technology adopted in North America and Europe are also used and adopted in the Middle East. This provides a common platform for joint research.

From this description, one may conclude that it is feasible for researchers and organizations in the Middle East to contribute to the usage and development of learning objects.

\section{Weaknesses}

The challenges to be encountered in implementing and using learning objects in the Middle East are very much the same as those in other parts in the world. One of the main challenges is that all the parties involved must agree on standards. For example, when it comes to metadata, what standards may be used? Will it be IMS? Dublin Core? Other standards? A second major challenge is the fundamental issue of the language used. The local languages in the Middle East are not English. 
A Critique Of Stephen Downes' Article, "Learning Objects": A Middle Eastern Perspective

\section{References}

Downes, S. (2001). Learning objects. International Review of Research in Open and Distance Learning 2(1). Available:

http://www.irrodl.org/content/v2.1/downes.html

Wieseler, W. (1999). RIO: A standards-based approach for reusable information objects. Cisco Systems White Paper. Retrieved June 26, 2001:

http://www. coursenet.com/media/pdf/RIO_Whitepaper_techlearn.do.pdf

Citation Format

Shata, Osama (2001) A Critique Of Stephen Downes' Article, "Learning Objects": A Middle

Eastern Perspective. International Review of Research in Open and Distance Learning: 2, 1.

http://www.icaap.org/iuicode?149.2.1.3

International Review of Research in Open and Distance Learning 